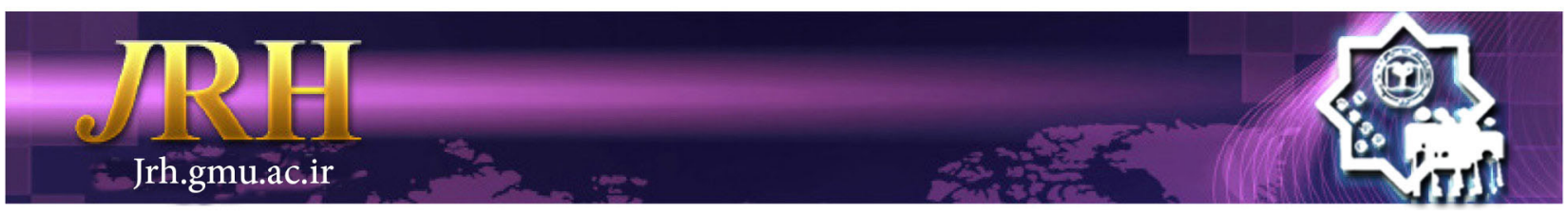

\title{
Social capital on the basis of spectating sports
}

Mojtaba Rajabi ${ }^{1}$, Mahdi Talebpour ${ }^{1}$, Zahed Ghaderi ${ }^{2}$, Hasan Assadi ${ }^{3}$

\author{
Journal of Research \& Health \\ Social Development \& Health Promotion \\ Research Center \\ Vol. 9, No. 5, Sep \& Oct 2019 \\ Pages: $394-400$ \\ DOI: 10.29252/jrh.9.5.394 \\ Original Article
}

1. Department of Sport Sciences, Faculty of Literature \& Human Science, University of Zabol, Zabol, Iran

2. Department of Business Management, Faculty of Management, Kharazmi University, Tehran, Iran

3. Department of Sport Management, Faculty of Physical Education and Sports Sciences, University of Tehran, Tehran, Iran

Correspondence to: Mahdi Talebpour, Department of Sport Management, Faculty of Sport Sciences, Ferdowsi University of Mashhad, Iran

Email: mtalebpour@um.ac.ir

Received: 4 Feb 2019

Accepted: 28 May 2019

How to cite this article: Rajabi M, TalebpourM, Ghaderi Z, Assadi H. Social capital on the basis of spectating sports. $J$ Research Health2019; 9(5): 394- 400.

\begin{abstract}
As a determinant of social health, attention has been paid to social capital, and also to sport as one of the ways of developing and accelerating the development of social capital. The purpose of this study is to investigate the social capital from the volleyball nations league perspective of sport spectators. The research was a cross-sectional study carried out using random sampling on 456 volleyball nations league spectators. Gibson et al.'s questionnaire was used to collect the data. "Trust and security" had the highest meaning among the social capital aspects, There was no significant difference between men's and women's social capital. A significant difference was observed only in terms of the "trust and security" dimension between the social capital of single and married individuals. Furthermore, in terms of social relationships and individuals with a master's degree and higher, the different aspects of social capital based on education were significantly different than those holding a bachelor's degree. Sport contests can be regarded as one of the generators of social capital in society. In addition, authorities can improve the social capital of society by planning and creating suitable conditions for these people and by taking into account their demographic status.
\end{abstract}

Keywords: Men, Social Capital, Sports, Women

\section{Introduction}

Health is the most important part of the welfare of society and is more dependent on social dependence than on medical interventions. Meanwhile, social capital is associated with almost all human and social and health issues due to its nature and content [1]. In fact, the concept of social capital is affiliated with society [2] Thus, Putnam sees social capital as the elixir of all the pains of society because a society's social capital is healthier, more affable, and perhaps more decisive and tolerant, and leads to a good and efficient government [3].Social capital attempts to describe the quality and quantity of interactions in society and their characteristics, such as social networks, trust and interrelationships, are used as an explanation for the difference in the health of places between places or between different groups, and this is one of the factors that increasingly affects health and well-being [4].Coleman, proclaims that social capital is the power of people to communicate with each other in the 
definition of social capital [5], Bourdieu. also identifies social capital as a collection of actual and potential sources that create a sustainable network of more or less intrusive interactions due to the familiarity and acceptance of others [6]. Thus, when people who have not already understood each other come together, the history of social capital becomes evident [7]. Studies also show that strengthening social capital contributes to individual participation and association, which plays an important role in improving individual quality of life [8] Brown et al. described the promotion of social capital as one of health improvement strategies [9]. Not saying, of course, that low social participation and lack of social support will also have a negative impact on people's health [10]. Social capital is therefore a multidimensional topic involving different dimensions of the social structure [7]. Shiani et al. examined young people's social capital in Iran and showed that social capital was weak, particularly in the dimension of relationships and trust in strangers and officials, and that individual and social characteristics might affect social capital [11]. Consequently, one of the factors associated with social capital is indicators such as the occupation, income and education of individuals [12]. Moradian Sorkhlaee et al. noted that certain areas of social capital are related to variables such as economic status, gender, location, and study area [13]. An emmerik, studied the gender difference in the creation of social capital in her research [14]. Rezaei et al. showed that the highest mean was related to communication with friends and family among the domains of social capital, and there was a significant relationship between social capital and demographic and educational variables [15]. In their research, Rimaz et al. found a meaningful relationship between education and the component of participation in women-headed households ' social capital group work [16]. Meanwhile, civic participation networks such as neighborhood associations, sports clubs and cooperatives are an essential form of social capital, and since these networks are more dense, community members are more likely to work for mutual benefit [6]. It is therefore possible to create social capital through sports and in the dominant part of a group of spectators who are the same audience [17]. Sport spectators, in fact, are people interested in watching sporting events [18]. A U.S. study showed that more than 10 percent of its people attend at least once a week a sporting event [19]. Active people in the field of sport have been determined to have higher social capital and thus have higher social trust [20]. In their research, Parsamehr et al. found a meaningful relationship between social capital components and sport watching [21]. Atherley. argued that consumption of sports could give social networks their form and function [22].

In fact, while maintaining the survival of the community's physical and mental health, sport as one of the individual-social manifestations helps to properly play the role of personal, family, and social [23]. Therefore, there is a reciprocal relationship between sport and society, as in the past, due to the reflection of social relationships and community culture, more emphasis has been placed on the impact of society on exercise, but researchers have sought to examine the impact of exercise on society in recent years. Now, given that social capital research in the field of sport is becoming an important area of research and the growing popularity of sporting activities in recent decades, the importance of strengthening social capital through sport can create a common, strong collective spirit to socialize and institutionalize individuals' sustainable health behaviours. Therefore, in this research, we are trying to examine the social capital of people who have closely watched the League of the volleyball nation and answer questions on how men and women watch the competition on their social capital? And is spectators with different demographic characteristics differing in social capital?

\section{Method}

This study is a cross-sectional study carried out in the field and is a type of applied research in terms of results. The research took place in Tehran (Azadi Stadium), Iran from 22-24 June 
2018. A questionnaire of 13 questions was used to measure social capital, based on the study by Gibson et al [17] as well as expert and consultant guidance. In this questionnaire, social capital consisted of four social partnership dimensions, four items, trust and security, four items, social relations, three items, life value, two items and measured by Likert Scale (very little to very high). 10 professors in this field reviewed the validity of the questionnaire face and content. The questionnaire's reliability was obtained using the alpha coefficient of Cronbach and, considering that the alpha coefficient was higher than 0.7 for all variables, the questionnaire's reliability was confirmed. This study's statistical community was the event's audience, a total of 31,300. Using the Cochran formula, the sample size was chosen by 446 participants.

To obtain complete information on individual views, 500 questionnaires were randomly distributed at the venue in 2018 at the time of the volleyball nation league. 44 of them were excluded due to distortion after the survey was completed and 456 questionnaires were finally analyzed.

To obtain frequency and percentage of frequency, mean, and standard deviation, descriptive statistics were used. Games-Howell analyzes and follow-up tests were used to test the research hypothesis. All questionnaires were analyzed at a significant level of 0.05 , (SPSS20).

\section{Results}

Of the 456 participating respondents, $341(75 \%)$ were male and $115(25 \%)$ were female. Participants' marital status was mostly single: $242(53 \%)$ and 214 married (47\%) ; respondents aged $141(30 \%)$ between the ages of 15 and $25,112(24 \%)$ between the ages of 26 and 35 , and $116(25 \%)$ between the ages of 36 and 45 and $87(19 \%)$ over 45 . As far as education is concerned, $72(15 \%)$ had diploma and post-diploma education, 32(7\%) had undergraduate degrees, 205(45\%) graduate students, and $147(32 \%)$ had master degrees or higher.

The mean of all social capital variables is higher than normal, according to the onesample t-test, and the difference from the mean of 3 is also significant in relation to $t$ and sig (Table 1). Watching these matches therefore

Table 1 The results of one-sample t-test to determine the priority of social capital

\begin{tabular}{lccccccc}
\hline \multirow{2}{*}{$\begin{array}{l}\text { Dimensions of social } \\
\text { capital }\end{array}$} & \multicolumn{7}{c}{ Test Value $=3$} \\
\cline { 2 - 8 } & Mean & $\mathrm{t}$ & $\mathrm{df}$ & Mean Difference & Upper & Lower & sig. \\
\hline Social capital & 3.63 & 20.74 & 455 & 0.63 & 0.70 & 0.57 & 0.000 \\
Social participation & 3.53 & 12.82 & 455 & 0.53 & 0.61 & 0.45 & 0.000 \\
Trust and safety & 3.76 & 17.24 & 455 & 0.76 & 0.85 & 0.67 & 0.000 \\
Social relationships & 3.68 & 21.57 & 455 & 0.68 & 0.74 & 0.61 & 0.000 \\
Value of life & 3.47 & 12.33 & 455 & 0.47 & 0.70 & 0.57 & 0.000 \\
\hline
\end{tabular}

Table 2 T-test results to examine the differences in the components of social capital by gender and marriage

\begin{tabular}{|c|c|c|c|c|c|c|c|c|c|c|c|c|}
\hline $\begin{array}{l}\text { Dimensions of } \\
\text { social capital }\end{array}$ & Sex & Mean & Upper & Lower & $\mathrm{t}$ & sig. & $\begin{array}{l}\text { Marital } \\
\text { status }\end{array}$ & Mean & Upper & Lower & $\mathrm{t}$ & sig. \\
\hline \multirow{2}{*}{ Social capital } & $\mathrm{M}(341)$ & 3.62 & \multirow{2}{*}{0.06} & \multirow{2}{*}{0.07} & \multirow{2}{*}{1.00} & \multirow{2}{*}{0.37} & $S(242)$ & 3.68 & \multirow{2}{*}{0.22} & \multirow{2}{*}{-0.01} & \multirow{2}{*}{1.67} & \multirow{2}{*}{0.09} \\
\hline & W(115) & 3.69 & & & & & $\mathrm{M}(214)$ & 3.58 & & & & \\
\hline \multirow{2}{*}{$\begin{array}{l}\text { Social } \\
\text { participation }\end{array}$} & $\mathrm{M}(341)$ & 3.52 & \multirow{2}{*}{0.16} & \multirow{2}{*}{-0.21} & \multirow{2}{*}{0.29} & \multirow{2}{*}{0.77} & $\mathrm{~S}(242)$ & 3.56 & \multirow{2}{*}{0.23} & \multirow{2}{*}{-0.08} & \multirow{2}{*}{0.88} & \multirow{2}{*}{0.37} \\
\hline & $\mathrm{W}(115)$ & 3.55 & & & & & $\mathrm{M}(214)$ & 3.43 & & & & \\
\hline \multirow{2}{*}{$\begin{array}{l}\text { Trust and } \\
\text { safety }\end{array}$} & $\mathrm{M}(341)$ & 3.73 & \multirow{2}{*}{0.084} & \multirow{2}{*}{-0.31} & \multirow{2}{*}{1.13} & \multirow{2}{*}{0.25} & $\mathrm{~S}(242)$ & 3.86 & \multirow{2}{*}{0.38} & \multirow{2}{*}{0.03} & \multirow{2}{*}{2.36} & \multirow{2}{*}{0.01} \\
\hline & $\mathrm{W}(115)$ & 3.85 & & & & & $\mathrm{M}(214)$ & 3.65 & & & & \\
\hline \multirow{2}{*}{$\begin{array}{l}\text { Social } \\
\text { relationship }\end{array}$} & $\mathrm{M}(341)$ & 3.66 & \multirow{2}{*}{0.06} & \multirow{2}{*}{-0.22} & \multirow{2}{*}{1.10} & \multirow{2}{*}{0.27} & $S(242)$ & 3.68 & \multirow{2}{*}{0.13} & \multirow{2}{*}{-0.11} & \multirow{2}{*}{0.178} & \multirow{2}{*}{0.85} \\
\hline & $\mathrm{W}(115)$ & 3.74 & & & & & $\mathrm{M}(214)$ & 3.67 & & & & \\
\hline \multirow{2}{*}{ Value of life } & $\mathrm{M}(341)$ & 3.45 & 009 & -025 & 087 & 038 & $S(242)$ & 3.53 & 028 & 0.01 & 174 & 008 \\
\hline & $\mathrm{W}(115)$ & 3.53 & 0.03 & -.020 & 0.01 & 0.00 & $\mathrm{M}(214)$ & 3.40 & 0.20 & -0.01 & 1.17 & 0.00 \\
\hline
\end{tabular}


has an effect on individuals' social capital and also has the greatest impact on individuals' trust and security.

The social capital of men and women watching the matches was examined by t-test after examining the normality of the data (Table 2). Social capital and its dimensions (social participation, trust and security, social relationships and the value of life) do not differ significantly between the two groups of men and women according to the values mentioned. Independent $t$-tests were also used to examine single and married spectators' social capital.

The results of the test showed that there is no significant difference between the overall social capital and the dimensions of social participation, social relationships and the value of life in both married and single groups, but the mean individuals were more than married in the dimension of trust and security (Table 2).

To investigate the differences between different educational groups in the dimensions

Table 3 Analysis of variance analysis to examine the differences between social capital components in terms of education

\begin{tabular}{llcccc}
\hline \multicolumn{1}{c}{ Variable } & Sum of squares & Mean square & $\mathrm{f}$ & sig. \\
\hline \multirow{4}{*}{ Social capital } & Between Group & 1.48 & 0.49 & & \\
& Within Group & 195.67 & 0.43 & 1.13 & 0.33 \\
& Total & 197.15 & & & \\
\hline \multirow{3}{*}{$\begin{array}{l}\text { Social } \\
\text { participation }\end{array}$} & Between Group & 0.60 & 0.20 & & \\
& Within Group & 358.32 & 0.79 & 0.25 & 0.85 \\
& Total & 358.92 & & & \\
\hline \multirow{3}{*}{$\begin{array}{l}\text { Trust and } \\
\text { safety }\end{array}$} & Between Group & 3.13 & 1.04 & & \\
& Within Group & 405.76 & 0.89 & 1.16 & 0.32 \\
& Total & 408.89 & & & \\
Social & Between Group & 4.11 & 1.37 & & \\
relationships & Within Group & 203.22 & 0.45 & 3.05 & 0.02 \\
& Total & 207.33 & & & \\
\hline \multirow{3}{*}{ Value of life } & Between Group & 1.86 & 0.62 & & \\
& Within Group & 302.54 & 0.66 & 0.92 & 0.42 \\
& Total & 304.40 & & & \\
\hline
\end{tabular}

Table 4 Results from Games-Howell for comparison of social relationships based on education

\begin{tabular}{|c|c|c|c|c|c|c|}
\hline Variable & Edu & ups & Mean difference & Upper & Lower & sig. \\
\hline \multirow{12}{*}{$\begin{array}{l}\text { Social } \\
\text { relationships }\end{array}$} & \multirow{3}{*}{1} & 2 & 0.184 & 0.60 & -0.24 & 0.66 \\
\hline & & 3 & 0.187 & 0.40 & -0.03 & 0.12 \\
\hline & & 4 & -0.004 & 0.21 & -0.22 & 1.00 \\
\hline & \multirow{3}{*}{2} & 1 & -0.184 & 0.24 & -0.60 & 0.66 \\
\hline & & 3 & 0.003 & 0.41 & -0.40 & 1.00 \\
\hline & & 4 & -0.188 & 0.22 & -0.59 & 0.60 \\
\hline & \multirow{3}{*}{3} & 1 & -0.187 & 0.03 & -0.40 & 0.12 \\
\hline & & 2 & -0.003 & 0.40 & -0.41 & 1.00 \\
\hline & & 4 & -0.192 & -0.01 & -0.37 & 0.03 \\
\hline & \multirow{3}{*}{4} & 1 & 0.004 & 0.22 & -0.21 & 1.00 \\
\hline & & 2 & 0.188 & 0.59 & -0.22 & 0.60 \\
\hline & & 3 & 0.192 & 0.37 & 0.01 & 0.03 \\
\hline
\end{tabular}

of social capital, variance analysis and GamesHowell test (due to variance inequality) were used, as described in Tables 3 and 4.

As can be seen in Table 3, social capital and its dimensions only make a significant difference between the four educational groups in social relations. In order to determine the difference between the groups (Group 1: Diploma and 
less, Group 2: Graduate Diploma, Group 3: Bachelor, Group 4: Masters degree and above), the Games-Howell test described in Table 4 was used in the Social Relationship variable. The results of this test showed that people with a Masters degree have higher social relationships than those with a Bachelor degree.

\section{Discussion}

Among the social capital dimensions, the highest mean was assigned to the dimensions of "trust and security" (3.76), "social relations" (3.68), "social participation" (3.53), and the lowest mean of "value of life" (3.47). Putnam. states that trust is one of the most important components of social capital from the point of view of social capital theorists [7]. Indeed, watching these events will increase the sense of trust between people and society and increase people's sense of security by organizing the event. The organization of these competitions will also make people feel safer on the nights of the event, in line with the results of $[17,20]$. Social relations were introduced as the second dimension of social capital, in line with the results of $[7,8,15,17]$. Watching these matches in social relationships will increase the social interactions of individuals in the community and people will become more involved with their friends during the event and have lasting friendships in the future. Ward and Tampubolon. therefore came to research on social capital, networks and recreational use, which showed that social capital was derived from friendships and recreational activities [24].

Social participation was introduced as the third dimension of social capital resulting from watching, consistent with the results of $[6,8,16,17,1]$. Watching these competitions will increase people's voluntary activities in the community and increase people's participation in working groups and society. Thus, Putnam. considers membership and participation in groups of horizontal order (sports clubs, voluntary unions, etc.) as one of the essential forms of social capital [7].

Life value was introduced as the fourth dimension and the lowest mean social capital derived from the observation of the event, consistent with the results of $[15,17]$. In fact, although it has the lowest mean social capital, the value of this dimension is greater than the mean, so organizing and watching these competitions in this city will make viewers feel valuable in this community and value the city and the country by organizing this event. The dimensions of social capital (social participation, social relationships, trust and security, and the value of life) are not significantly different from those seen in men and women by spectators that are not consistent with the results of $[11,13,14]$. In the differences between the studied communities and how social capital is investigated in the statistical population, non-consistency can be observed. However, the number of women spectators was lower than that of men due to the existing rules, but the men and women present at the event reported a high level of social capital and all organized the event, creating social capital among the people. The results showed that there is no significant difference in both married and single groups between the total social capital and the dimensions of social participation, social relationships and life value. But there was a significant difference in the trust and security dimension The mean individuals were more than married. Rezaei et al. concluded that only the difference in the value of life between individuals and married persons is different from the results of this research [15]. It can therefore be said that individuals are interested in loneliness with different people and this relationship will increase the sense of trust between these people, while married people have the greatest sense of trust and security with their families.

The results showed that the four educational groups were only significantly different from the general social capital and the four dimensions of social capital in the dimension of social relations and those with a master's degree or higher had a higher social relationship than those with a bachelor's degree, consistent with [16]. On the other hand, Rezaei et al. 
described differences in trust, security, and value of life variables [15]. Striving for community participation and helping to solve social problems are more prominent among people with a high education degree due to growing age and greater experience leading to increased social relationships among these people. Increasing the educational and training levels associated with the increase in academic years will therefore be among the elements affecting social capital [16].

\section{Conclusion}

The results showed that watching sporting competitions as one of social capital generators can be considered as a reliable strategy for social capital promotion. It is therefore suggested that the relevant authorities provide precise planning and facilities for those interested in watching sporting events to increase social capital. It is also suggested that we also increase the level of social capital in these areas by organizing these competitions in other Iranian cities. Since spectators ' demographic status is related to social capital, it can be appropriated through appropriate interactions between individuals and institutions that the related party attempted to increase social capital. With regard to the research constraints, it can be said that the cross-sectional nature of this study affects the generalization of the research results and the lack of cooperation between a number of people to complete the questionnaires.

\section{Acknowledgments}

The current research is based on $\mathrm{PhD}$ dissertation of Ferdowsi University, Mashhad, Iran. The authors are grateful to all the people who contributed to this study.

\section{Authors' contributions}

Study design: MR, MT

Data collection and analysis: MR, ZG, HA

Manuscript preparation: MT, ZG, HA

All authors have read and approved the final version.

\section{Conflict of Interest}

"The authors declare that they have no competing interests."

\section{Funding}

The authors received no financial support for the research, authorship and/or publication of this article.

\section{Availability of data and materials}

The datasets used and/or analyzed during this study are available from the corresponding author on reasonable request.

\section{References}

1- Bahrami M, Amiri A, Montazeralfaraj R, Dehghan H. The relationship between social capital dimensions and perceived health in Yazd Urban society, 2013. The Journal of Toloo-E-Behdasht2016; 15(3): 67-77.

2- Noghani M, Razavizadeh N. Social capital and health: a return to social and sociological traditions. $J$ Research Health2013; 3(1): 286-94

3- Sabatini F. The role of social capital in economic development: Investigating the causal nexus through structural equations models. Social Capital Gateway2005; 3(4): 1-27.

4- Drukker M, Buka SL, Kaplan C, McKenzie K, Van Os J. Social capital and young adolescents' perceived health in different sociocultural settings. Journal of Social Science \& Medicine2005; 61(1): 185-98.

5 - Coleman JS. Social capital in the creation of human capital. Am J Sociol1988; 94: 95-120.

6- Bourdieu P. The forms of capital. In: Richardson J, ed. Handbook of theory and research for the sociology of education. Westport: Greenwood; 1986. pp: 241-58.

7- Putnam RD. Bowling alone: The collapse and revival of American community. New York: Simon \& Schuster; 2000.

8- Abdul-Hakim R, Abdul-Razak NA, Ismail R. Does social capital reduce poverty? A case study of rural households in Terengganu, Malaysia. Eur J Soc Sci2010; 14(4): 556-66.

9- Brown TT, Scheffler RM, Seo S, Reed M. The empirical relationship between community social capital and the demand for cigarettes. Health Econ2006; 15(11): 1159-72.

10- Herzog AR, Ofstedal MB, Wheeler LM. Socialengagement and its relationship to health. Clin Geriatr Med2002; 18(3): 593-609.

11- Shiani M, Mosavi M, Madani-Ghahghrkhi S. Social capital of young people in Iran. Iranian Journal of Sociology2009; 1(3): 57-84.

12- Rahnamafalavarjani Z, Kiyani M. The impact of feeling gender inequality on social capital at Isfahan 
educated women. Journal of Applied Sociology2015; 26(2): 77-90.

13- Moradian Sorkhkalaee M, Eftekhar Ardebili H, Naz Nejat S, Saiepour N. Social capital among Tehran university of medical sciences students in 2011. Razi Journal of Medical Sciences2012; 19(102): 31-7.

14- Van Emmerik IH. Gender differences in the creation of different types of social capital: A multilevel study. Soc Network2006; 28(1): 24-37.

15- Rezaei F, Yaseri M, Jahangiri L, Nejat S. A survey on social capital in the students of Jahrom university of medical sciences in 2014. Journal of Rafsanjan University of Medical Sciences2016; 15(4): 295-306.

16- Rimaz S, Moradi Y, Abolghasemi J. Explore the factors affecting components of social capital in womenheaded households by using confirmation analysis. Razi Journal of Medical Sciences2015; 22(135): 140-8.

17- Gibson HJ, Walker M, Thapa B, Kaplanidou K, Geldenhuys S, Coetzee W. Psychic income and social capital among host nation residents: A pre-post analysis of the 2010 FIFA World Cup in South Africa. Tour Manag2014; 44: 113-22.

18- Saatchian V, Elahi A, Nazemi M, Alizadeh, A.
Priories the factors of fans supportive reasons and the relationship with attendance and their supporting in Iran Pro league. Journal of Sport Management Review2012; 4(11): 137-54.

19- Douvis J, Douvis S. A review of the research areas in the field of sport marketing: Foundations, current trends, future directions. The Cyber-Journal of Sport Marketing2000; 4(3)

20- Seippel Ø. Sports in civil society: Networks, social capital and influence. Eur Socio Rev2007; 24(1): 69-80. 21- Parsamehr M, Jesmani S. Social capital role on sport consumption (Spectating): The study in Yazd City Youth. Research in Sport Management \& Motor Behavior2011; 1(1): 73-84.

22- Atherley KMJGR. Sport, localism and social capital in rural Western Australia. Geographical Research2006; 44(4): $348-60$.

23- Eslami Marzankolateh MM, Moosavi SJ, Khoshfar G. Relationship between social capital and participation in sports activities (Case: Womens in Gorgan). Social Capital Management2014; 1(2): 139-59.

24- Warde A, Tampubolon G. Social capital, networks and leisure consumption. Sociol Rev2002; 50(2): 155-80.

Copyright(C) 2016 ASP Ins. This open-access article is published under the terms of the Creative Commons Attribution-NonCommercial 4.0 International License which permits Share (copy and redistribute the material in any medium or format) and Adapt (remix, transform, and build upon the material) under the Attribution-NonCommercial terms. 